Tropical Journal of Pharmaceutical Research December 2011; 10 (6): 697-703

(C) Pharmacotherapy Group, Faculty of Pharmacy, University of Benin

Benin City, 300001 Nigeria.

All rights reserved.

Available online at http://www.tjpr.org

Research Article

http://dx.doi.org/10.4314/tjpr.v10i6.1

\title{
Development and Evaluation of Proniosome- Encapsulated Curcumin for Transdermal Administration
}

\section{Kapil Kumar ${ }^{1}$ and AK Rai ${ }^{2}$}

Institute of Pharmacy, NIMS University, Jaipur, 303121, Rajasthan, Global Institute of Pharmaceutical Education and Research, Kashipur, UK; ${ }^{2}$ Pranveer Singh Institute of Technology, Kanpur, U.P., India

\begin{abstract}
Purpose: To develop a proniosomal carrier system of curcumin for transdermal delivery.

Methods: Proniosomes of curcumin were prepared by encapsulation of the drug in a mixture of Span 80, cholesterol and diethyl ether by ether injection method, and then investigated as a transdermal drug delivery system (TDDS). The formulated systems were characterized for size, drug entrapment, angle of repose, hydration rate and vesicular stability under various storage conditions. In vitro release studies were performed using albino rat skin.

Results: The method used for preparing proniosome resulted in an encapsulation yield of $82.3-86.8 \%$. Scanning electron microscopy analysis showed that the surface of the particles was smooth. Stability data following storage under different conditions showed that the drug content of the proniosomes varied from 99.5\% under refrigerated condition to 99.2 and $93 \%$ at room and elevated temperatures, respectively. One of the formulations (PG1) showed prolonged in vitro drug release of $61.8 \%$ over a period of $24 \mathrm{~h}$.

Conclusion: It is evident from this study that proniosomes are very stable and promising prolonged delivery system for curcumin.
\end{abstract}

Keywords: Proniosomes, Curcumin, Drug stability, In vitro release, Transdermal drug delivery. 


\section{INTRODUCTION}

Niosomes or nonionic surfactant vesicles are microscopic lamellar structures formed on admixtures of nonionic surfactant of the alkyl or dialkyl polyglycerol ether class and cholesterol with subsequent hydration in aqueous media [1]. Since the structure of the niosome accommodate hydrophilic, lipophilic as well as ampiphilic drug moieties, they can be used as delivery device for various drugs [2]. Proniosome gel is an intermediate state of formation of niosome. The niosomes can be prepared from the proniosomes by adding the aqueous phase with the drug to the proniosomes with brief agitation at a temperature above the mean transition temperature of the surfactant [3]. Proniosome possess different advantages over niosome i.e. it is not susceptible to instability problems like aggregation, fusion, leaking and hydrolysis of encapsulated drugs which limits the shelf life of the dispersion[4].

Curcuminoids are oleoresins, derived from the ethanolic extraction of turmeric. They are primarily responsible for the yellow coloration as well as biological activity. Earlier studies have shown that curcumin has a wide range of therapeutic effects such as antiinflammatory [5] , antibacterial [6], antifungal [7], anticancer [8] antispasmodic [9], antioxidant [10], antiamoebic [11] , anti HIV [12], antidiabetic [13], antifertility [14] etc. It is reported to be very safe with a toxicity profile of $8 \mathrm{~g} /$ day. Studies on the pharmacokinetics of curcumin indicates its poor solubility in acid medium and consequently very low absorption from the GIT. Furthermore, there is extensive systemic metabolism hence its delivery problems and lack of clinical success [15]. This ultimately leads to poor bioavailability by oral administration. Curcumin is already in use by topical and oral administration. By the means of transdermal drug delivery system all these can be avoided and therapeutic efficacy of curcumin can be improved. In this present study, proniosomal gel of curcumin have been prepared for transdermal drug delivery.

\section{EXPRIMENTAL}

\section{Materials}

Curcumin was obtained as the gift from Krish Enterprise, Mumbai, India. Span 80 was purchased from $\mathrm{CDH}$, Delhi. All other chemicals used were of analytical grade.

\section{Ether injection process}

Proniosomes containing curcumin of $1: 1$ ratio (PG4) were prepared by dissolving cholesterol $(50 \mathrm{mg})$ and Span $80(50 \mathrm{mg})$ in $2 \mathrm{ml}$ diethyl ether and the solution was injected slowly $(0.25 \mathrm{ml} / \mathrm{min})$ into a beaker containing $200 \mathrm{mg}$ curcumin in $10 \mathrm{ml}$ phosphate buffer $(\mathrm{pH} 7.4)$. The temperature was maintained at $40-60{ }^{\circ} \mathrm{C}$ during the injection. The differences in temperature between the phases caused rapid vaporization of the ether resulting in spontaneous vesiculation [16,17]. Three other formulations were similarly prepared using cholesterol and Span 80 in the ratios 1:2, 1:3 and 1:4 (see Table 1)

Table 1: Composition of formulations*

\begin{tabular}{cccc}
\hline $\begin{array}{c}\text { Formulation } \\
\text { Code }\end{array}$ & $\begin{array}{c}\text { Span } \\
80 \\
(\mathrm{mg})\end{array}$ & $\begin{array}{c}\text { Cholesterol } \\
(\mathrm{mg})\end{array}$ & $\begin{array}{c}\text { Span/ } \\
\text { Cholesterol } \\
\text { ratio }\end{array}$ \\
\hline PG1 & 50 & 200 & $1: 4$ \\
PG2 & 50 & 150 & $1: 3$ \\
PG3 & 50 & 100 & $1: 2$ \\
PG4 & 50 & 50 & $1: 1$ \\
\hline Each formulation contained diethyl ether $(2 \mathrm{ml})$, drug $(50$
\end{tabular}
$m g$ )

\section{Vesicle size determination}

An optical microscope (model) with a calibrated eyepiece micrometer was used. The diameter of the particles appearing under the field of view were measured until about 200 niosomes were measured individually, and their size range and mean diameter were calculated 


\section{Drug content}

Proniosomes formulation equivalent to $40 \mathrm{mg}$ of curcumin was taken into a standard volumetric flask. They were lysed with $100 \mathrm{ml}$ of propane-1-ol by shaking and $1 \mathrm{ml}$ of the mixture subsequently diluted with phosphate buffer (pH 7.4). The absorbance was measured spectrophotometrically at $254 \mathrm{~nm}$ and drug content calculated from the calibration curve of curcumin in phosphate buffer ( $\mathrm{pH} 7.4)$.

\section{Scanning electron microscopy studies}

(SEM)

Pure drug and selected formulations were sputtered coated using pelco gold palladium coaters. The surface morphology of the layered sample was examined using SEM. The samples were placed in an evacuated chamber and scanned in a controlled pattern by an electron beam. Interaction of the electron beam with the specimen produces a variety of physical phenomenon which when detected, are used to form images and provides information about the specimens. [18]

\section{Drug entrapment efficiency of niosomes}

Entrapment efficiency of niosomes was determined by exhaustive dialysis method. The measured quantity of niosomal suspension was taken into a dialysis tube to which osmotic cellulose membrane was securely attached on one side. The dialysis tube was suspended in $100 \mathrm{ml}$ phosphate buffer ( $\mathrm{pH}$ 7.4), which was stirred on a magnetic stirrer. The unentrapped drug was separated from the niosomal suspension into the medium through osmosis cellulose membrane. At every hour entire medium $(100 \mathrm{ml})$ was replaced with fresh medium (for about 9-12 hrs) till the absorbance reached a constant reading indicating no drug is available in unentrapped form. The niosomal suspension in the dialysis tube was further lysed with propane-1-ol and estimated the entrapped drug by UV spectrophotometric method at $254 \mathrm{~nm}$. Entrapment efficiency (E) was calculated using Eq 1 [19].

$E(\%)=100(T D-D D) / T D$

where TD is total drug and DD is diffused drug

\section{Measurement of angle of repose}

Angle of repose of dry proniosome of curcumin powder was measured by funnel method [20].. Proniosomes powder was poured into a funnel which was fixed at a position so that the $12 \mathrm{~mm}$ outlet orifice of the funnel is $5 \mathrm{~cm}$ above a surface. The powder flows down from the funnel to form a cone on the surface. Angle of repose was then calculated by measuring the height of the cone and the diameter of its base

\section{Rate of hydration (Spontaneity)}

Spontaneity of niosomes formation is described as the number of niosomes formed after hydration of proniosomes for $15 \mathrm{~min}$. Proniosomes were transferred to the bottom of a small stoppered glass tube and spread uniformly. One $\mathrm{ml}$ saline $(0.154 \mathrm{M} \mathrm{NaCl})$ was added carefully without agitation and the solution kept for about 15-20 min after which a drop of the aqueous layer was withdrawn and placed on Neubaur's chamber. The number of niosomes formed from proniosomes were counted.

\section{Stability studies}

The ability of vesicles to retain the drug (Drug Retention Behaviour) was assessed by keeping the proniosomal gel at three different temperature conditions, i.e., refrigeration $(4-$ $\left.8{ }^{\circ} \mathrm{C}\right)$, room $\left(25 \pm 2{ }^{\circ} \mathrm{C}\right)$ and oven $\left(45 \pm 2{ }^{\circ} \mathrm{C}\right)$. Throughout the study, proniosomal formulations were stored in aluminium foilsealed glass vials. The samples were withdrawn at different time intervals over a period of one month and drug leakage from the formulations was studied by determining drug content after storage for one month [21]. 


\section{In vitro skin permeation study}

The in vitro rat skin permeation study was carried out as per the guidelines compiled by the Committee for the Purpose of Control and Supervision of Experiments on Animal (CPCSEA), Ministry of Culture, Government of India and all the study protocols were approved by the local institutional Animal Ethics Committee PSIT, Kanpur, India. Also an international protocol for conducting experiments on animals were followed [22]. The abdominal hair of albino rats (wistar strain), weighing $200 \pm 20 \mathrm{~g}$, was shaved using a hand razor. Care was taken not to damage the skin surface. The rats were sacrificed by administration of excess chloroform inhalation and the abdominal skin of the rats were separated. The skin was stored at $-20^{\circ} \mathrm{C}$ and used within three days for the permeation study. It has been reported that storage in the refrigerator reduces the metabolic activity of the skin. Before the permeation study, the skin was hydrated in phosphate buffer $\mathrm{pH} 7.4$ (containing $0.02 \%$ sodium azide as a preservative) at $4^{\circ} \mathrm{C}$ over night and the adipose tissue layer of the skin was removed by rubbing with a cotton swab.

The permeation of drug from proniosomal gel formulations was determined by using Franz diffusion cell. The excised rat skin was mounted on the receptor compartment with the stratum corneum side facing upwards into the donor compartment. The donor compartment was filled with the proniosomal gel formulation. Phosphate buffer $(15 \mathrm{ml}, \mathrm{pH}$ 7.4) containing 10\% PEG was used as receptor medium to maintain a sink condition. The available diffusion area of the cell was $3.14 \mathrm{~cm}^{2}$. The receptor compartment was maintained at $37 \pm 1^{\circ} \mathrm{C}$, with a magnetic stirring at $600 \mathrm{rpm}$. The samples from the receptor compartment were withdrawn at predetermined time intervals and immediately replaced by an equal volume of fresh buffer solution. The samples withdrawn from the receptor compartment were then analyzed by using UV spectrophotometer at $254 \mathrm{~nm}$.

\section{Statistical analysis}

To ascertain drug release mechanism and release rate, the data were model fitted to various release models - zero order (Eq 2), Higuchi (Eq 3) and Korsmeyer-Peppas (Eq 4) - using PCP Disso V3.0 dissolution software $[23,24]$.

Release rate $=\mathrm{k} \ldots \ldots \ldots \ldots \ldots \ldots \ldots(2)$

Release rate $=\mathrm{kt}^{0.5}$

Release $=\mathrm{kt}^{\mathrm{n}}$

where $\mathrm{k}$ is aconstant, $n$ is the release exponent

\section{RESULTS}

The low cost, greater stability and resultant ease of storage of nonionic surfactant vesicles have lead to the exploitation of these vesicles as alternatives to phospholipids vesicles for the enhancement of dermal and/or transdermal bioavailability of drugs and substances [25].

SEM (Fig 1) shows that the niosomes prepared by ether injection method were small in size, unilamellar and spherical in shape with a smooth surface.

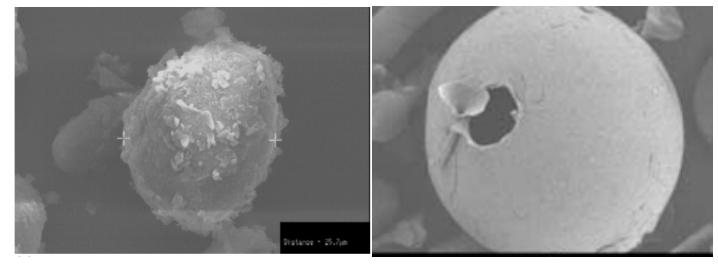

Figure 1: SEM of (a) pure curcumin and (b) formulation PG1 proniosomes

The results of the characterization of the curcumin proniosome formulations are shown in Table 2. 
Table 2: Some physicochemical characteristics of curcumin proniosomal formulations

\begin{tabular}{lccccc}
\hline $\begin{array}{l}\text { Formulation } \\
\text { code }\end{array}$ & $\begin{array}{c}\text { Entrapment } \\
\text { Efficiency }(\%)\end{array}$ & $\begin{array}{c}\text { Mean particle } \\
\text { size }(\mu \mathrm{m}, \pm \mathrm{SD}\end{array}$ & $\begin{array}{c}\text { Angle of Repose } \\
\left({ }^{\circ}\right)^{*}\end{array}$ & $\begin{array}{c}\text { Drug content } \\
(\%)^{*}\end{array}$ & $\begin{array}{c}\text { Rate of spontaneity } \\
\mathrm{Mm}^{3} \times 10^{3}\end{array}$ \\
\hline PG1 & $82.30 \pm 0.48$ & $3.84 \pm 0.35$ & $36.22 \pm 0.43$ & $89 \pm 0.42$ & $11.19 \pm 0.35$ \\
PG2 & $83.40 \pm 0.76$ & $4.66 \pm 0.35$ & $37^{\circ} .22 \pm 0.18$ & $85 \pm 0.20$ & $15.25 \pm 0.58$ \\
PG3 & $85.20 \pm 0.59$ & $4.25 \pm 0.35$ & $34^{\circ} .22 \pm 0.23$ & $82 \pm 0.83$ & $14.54 \pm 0.9$ \\
PG4 & $86.80 \pm 0.62$ & $4.32 \pm 0.35$ & $33^{\circ} .22 \pm 0.06$ & $84 \pm 0.55$ & $16.58 \pm 0.75$ \\
\hline
\end{tabular}

The proniosomes were in the size range 3.84 - $4.66 \mu \mathrm{m}$. Entrapment efficiency was $82.3 \%$ for PG1whereas it was $83.4,85.2 \%$, and 86.8, for formulations PG2, PG3 and PG4, respectively. Angle of repose of the formulation was between 33.2 and $36.2^{\circ}$. Drug content was highest in formulation PG1 containing (89\%). Rate of spontaneity was between 11.19 and 16.58. Stability data for formulation PG4 showed that drug content, after storage under various temperature conditions was $99.5 \%$ (refrigerated condition), $99.2 \%$ (room temperature) and $93.0 \%$ ( oven temperatures).

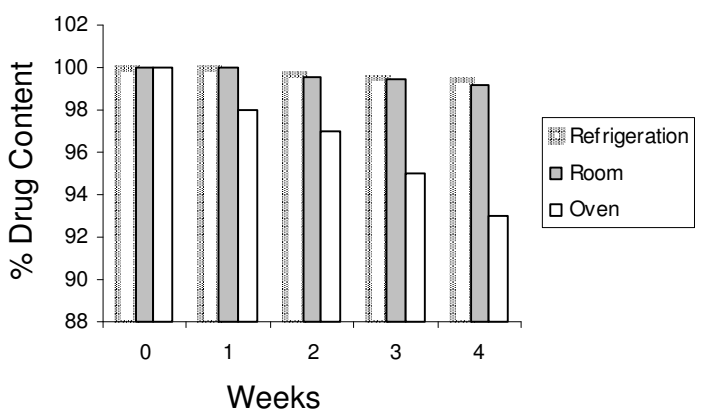

Figure 2: Stability of formulation PG4 under different conditions

Maximum in vitro skin release in $24 \mathrm{~h}$ was shown by formulation PG4 (78.5\%) and minimum $(61.8 \%)$ by formulation PG1.

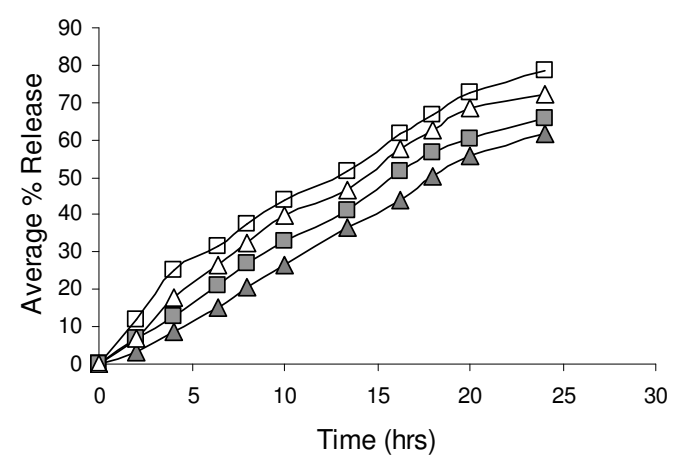

Figure 3: Cumulative curcumin permeation through rat abdominal skin from different curcumin niosome formulations (Key: $\mathbf{\Delta}=\mathrm{PG} 1$; PG2; $\Delta=$ PG3; $\square$ = PG4)

Kinetic parameters determined are shown in Table 3.

To ascertain drug release mechanism and release rate, the release data were fittedinto release models using PCP Disso V3.0 dissolution software. The models selected were zero order, Higuchi matrix and Korsmeyer-Peppas.

\section{DISCUSSION}

The objective in developing proniosomes was to devise a method of producing a nonionic surfactant based dosage form at the point of

Table 3: Drug release kinetic parameters for the formulations

\begin{tabular}{lccccccc}
\hline Formulation & \multicolumn{2}{c}{ Zero order } & \multicolumn{2}{c}{ Higuchi } & \multicolumn{2}{c}{ Korsmeyer-Peppas } \\
\cline { 2 - 8 } & $R$ & $K$ & $R$ & $K$ & Slope $(n)$ & $R$ & $K$ \\
\hline PG1 & 0.8461 & 1.2355 & 0.9825 & 10.0458 & 0.7562 & 0.9752 & 5.0038 \\
PG2 & 0.8124 & 1.0832 & 0.9755 & 8.8554 & 0.6658 & 0.9521 & 5.7985 \\
PG3 & 0.9052 & 1.3568 & 0.9935 & 10.1652 & 0.6521 & 0.9842 & 4.8856 \\
PG4 & 0.9121 & 1.4881 & 0.9928 & 10.1045 & 0.6843 & 0.9621 & 6.2541 \\
\hline
\end{tabular}


use to avoid problems of physical and chemical instability found in storage of some surfactant-based dosage forms. By creating a dry formulation, issues related to hydrolysis of the active ingredient or surfactants are avoided.

Curcumin is lipid soluble so dissolved in chloroform and dispersed uniformly throughout the composition. From the above study it was observed that as the cholesterol content in the vesicles increased, the incorporation of the drug in the vesicles also increased. Cholesterol is the known to increase the rigidity of the proniosomal membrane.

The order of encapsulation efficiency increases when the concentration of span-80 was increased. In all the niosomes prepared with spans, as the concentration of surfactant increased drug entrapment efficiency increased. The encapsulation efficiency of niosomes is governed by the ability of formulation to retain drug molecules in the aqueous core or in the bilayer membrane of the vesicles. Cholesterol improves the fluidity of the bilayer membrane and improves the stability of bilayer membrane in the presence of biological fluids such as blood/plasma. This characteristic of cholesterol decreasing leakage of bilayer structure and producing surface smoothness diminish at higher proportions as it imparts crystallinity to the bilayer

The amount of drug retained within the vesicles under defined conditions ultimately governs the shelf life of the drug. The results showed that proniosomal gel formulation was quite stable at refrigeration and room temperatures as not much leakage of drug was found at these temperatures (Figure 2). Percent drug retained at $45^{\circ} \mathrm{C}$ might have decreased due to the melting of the surfactant and lipid present in the formulation. Therefore, the proniosomal gel formulations can be stored at either refrigeration or room temperature. In vitro drug release studies (figure 3 ) indicate that in formulation PG1,
$76 \%$ of drug was released after 24 hours while PG3 and PG4 had lesser drug release after 24 hours. This showed that cholesterol formed a film around the vesicles and increased the micro viscosity of the bi-layer. The thickness of the film depends upon the concentration of cholesterol. Hence, inclusion of cholesterol improved drug retention time and thus reduced permeability. The value of $\mathrm{n}$ in Korsmeyer-Peppas model is less than 1, indicating Fickian diffusion and anomalous transport.

It is necessary to improve the bioavailability of curcumin in order to fully utilize the potential of this agent, and therefore a growing number of research groups are working on this aim. The study conducted by $\mathrm{Li}$ et al [24] investigated the effect of liposomal curcumin on pancreatic carcinoma cells and suppression of KF - kB activity [26]. The incorporated curcumin in liposome's showed a dose related increase in apoptosis of carcinoma cells and suppression of NF- B activity. The study conducted by Kunwar et al compared the cellular uptake of liposomal and albumin-loaded curcumin by the splenetic lymphocytes and EL4 lymphoma cells [27].

\section{CONCLUSION}

Proniosomal systems of curcumin made with Span 80 exhibited good physicochemical and release properties and can easily be prepared. Formulations prepared using Span 80 with cholesterol showed promising results. Proniosomes may be a promising carrier for curcumin and other drugs, especially due to their simple production and facile scale up. It is recommended that proniosomal formulations should be kept refrigerated to achieve best stability. The in-vitro permeation of curcumin from proniosomes of various compositions and types of nonionic surfactants have been studied and evaluated. However, in-vivo studies are required to prove their actual utility as vehicles for transdermal drug delivery. 


\section{ACNOWLEDGEMENT}

Authors are thankful to $\mathrm{Dr}$ AK Saxena, a scientist at G. CDRI, Lucknow, India, for his technical suggestions and motivation during the research work.

\section{REFERENCES}

1. Malhotra M, Jain NK. Niosomes as Drug Carriers. Indian Drugs (1994), 31 (3): 81-86.

2. Buckton G, Harwood, Interfacial phenomena in Drug Delivery and Targeting Academic Publishers, Switzerland. 1995; pp 154-155.

3. Hu C., Rhodes DG., Proniosomes: a novel drug carrier preparation. Int $j$ Pharm 2000; 206(1-2): 109-122

4. Ghatak N, Basu N. Sodium curcuminate as an effective antiinflammatory agent. Indian J. Exp. Biol.1972; 10: 235-236

5. Negi PS, Jayaprakash GK, Jagan MRL, Sakariah KK. Antibacerial activity of turmeric oil; $A$ byproduct from curcumin manufactuer. J.Agric. Food Chem. 1999; 47: 4297-300

6. Apisariyakul A, Vanittanakomm N, Buddhasukh D. Antifungal activity of turmeric oil extracted from Curcuma longa (Zingiberaceae). J. Ethnopharmacol.1995; 49: 163-169

7. Ghatak N, Basu, N. Sodium curcuminate as an effective antiinflammatory agent. Indian J. Exp. Biol.1972; 10: 235-236.

8. Itthipanichpong $C$, Ruangrungsi $N$, Kemsri $W$, Sawasdipanich A. Antispasmodic effects of curcuminioids on isolated guinea pig ileum and rat uterus. J. Med. Assoc. Thai. 2003; 86: 299309.

9. Ruby AJ, Kuttan G, Dinesh BK, Rajasekharan KN, Kuttan R. Antitumor and antioxidant activity of natural curcuminoids. Cancer Lett. 1995; 94: 79-83.

10. Dhar ML, Dhar MM, Dhawan BN, Mehrotra BN and Ray C. Screening of Indian plants for biological activity: I. Indian J. Exp.Biol. 1968; 6: 232-247.

11. Mazumdar A, Raghavan K, Weinstein J, Kohn KW and Pommer $Y$. Inhibition of human immunodeficiency virus type-1 integrase by curcumin. Biochem. Pharmacol.1995; 49: 1165-1170.

12. Halim EM, Ali H. Hypoglycemic, hypolipidemic and antioxidant properties of combination of curcumin from Curcuma longa Lin. and partially purified product from Abroma augusta Lin. In streptozotocin induced diabetes. Ind. J. Clinic.Biochem. 2002: 17(12): 33-43.

13. Garg SK. Effect of Curcuma longa (rhizomes) on fertility in experimental animals. Planta Med.
1974; 26: 225-227

14. Dhillon N, Aggarwal BB, Newman RA, Wolff RA, Kunnumakkara $A B$, Abbruzzese JL, Ng CS, Badmaev, Kurzrock R. Phase II trial of Curcumin in patients with advanced pancreatic cancer. Clin Cancer Res 2008; 14: 4491-4499.

15. Namdeo A., P.R, Mishra, A.J, Khopade, Jain N.K, Formulation and Evaluation of niosomes encapsulated Indomethacin, Indian Drugs, 36 (6), 1999; 378-380.

16. Liberman $H A$, Reiger $M$, Banker GS. In Pharmaceutical dosage forms - dispersed systems, ed $2 \mathrm{Vol} 2$, Marcel Dekker, New York, 1989; pp 567-602.

17. Mahmoud EB, Gihan F, Mohamed F. Improvement of solubility and dissolution rate of indomethacin by solid dispersions in Gelucire 50/13 and PEG4000. Saudi Pharm J 2009; 17: 217-225.

18. Hu C and Rhodes DG. Proniosomes: a novel drug carrier preparation. Int. J. Pharm. 1999; 185: 23-35.

19. Rhodes DG, Chengjiu H. Proniosomes: A Novel Drug Carrier Preparation. Int. J. Pharm. 1999; 185: 23-35.

20. Solanki A, Parikh R. Preparation, Characterization, optimization, and stability studies of Aceclofenac Proniosomes, Iranian J. Pharm Res. 2008; 7(4): 237-246.

21. Kuhara $T$. Consensus recommendations on effective institutional animal care and use committees. Information on Overseas Technologies in Laboratory Animal Science. 1988; 7: 14-17

22. Uchegbu IF, Vyas SP. Nonionic surfactant based vesicles (niosomes) in drug delivery. Int. J. Pharm. 1998: 172; 33-70

23. Korsmeyer RW, Gurny $R$, Doelker EM, Buri $P$, Peppas NA,. Mechanism of solute release from porous hydrophilic polymers. Int. $J$ Pharm. 1983; 15: 25-35.

24. Higuchi WI. Analysis of data on the medicament release from ointments. J. Pharm. Sci. 51; 802-804

25. Baillie AJ, Florence AT, Hume LR, Murhead GT. The preparation and properties of non ionic surfactant vesicles. J Pharm Pharmcol. 1985; 37: 863868

26. Li L, Braiteh F, Kurzrock R. Liposomeencapsulated curcumin in vitro and in vivo effects on proliferation, apoptosis, signaling, and angiogenesis. Cancer. 2005; 104: 1322 1331.

27. Kunwar A, Barik A, Pandey R, Priyadarsini KI. Transport of liposomal and albumin loaded curcumin to living cells: An absorption and fluorescence spectroscopic study. Biochimica et Biophysica Acta. 2006; 1760: 1513-1520. 